\title{
Autistic Phenotype of Permutation and Intermediate Alleles of FMR1 Gene
}

\author{
Mahmoud Shekari Khaniani, ${ }^{1}$ Fatemeh Amini Yeganeh, ${ }^{1}$ Shahrokh Amiri, ${ }^{2}$ and Sima Mansouri \\ Derakhshan ${ }^{1, *}$ \\ ${ }^{1}$ Department of Medical Genetics, Faculty of Medicine, Tabriz University of Medical Sciences, Tabriz, Iran \\ ${ }^{2}$ Research Center of Psychiatry and Behavioral Sciences, Tabriz University of Medical Sciences, Tabriz,Iran \\ "Corresponding author: Dr Sima Mansouri-Derakhshan, Department of Medical Genetics, Faculty of Medicine, Tabriz University of Medical Sciences, Tabriz, Iran. Tel: \\ +98-4133375540, E-mail: mderakhshan2002@gmail.com
}

Received 2016 October 23; Revised 2017 February 20; Accepted 2017 June 17.

\begin{abstract}
Background: Mutations in gene are the most common single genetic cause of autism-spectrum disorders, therefore we investigated the possibility that the intermediate alleles may also contribute to the origin of Autistic disorder.

Methods: We screened 96 males, recruited from North West of Iran, who were diagnosed with autistic disease for CGG repeat size. The frequencies of either intermediate or premutation alleles were matched with 168 male controls. All patients and normal controls were of Azeri Turkish ethnicity.

Results: Three mutated, five intermediate and four premutation carriers were identified among Autistic patients, compared with one premutation carrier in normal controls, representing a significant excess in small size FMR1 allele carriers $(=0.006)$. There was also a significant excess of the intermediate carriers compared with normal controls $(=0.006)$.

Conclusions: Both of these alleles may show roles in the etiology of autism, possibly as a result of the rise of mRNA. Considering that there are individuals in the general population are carriers of intermediate and premutation alleles, further screening of larger samples of Autism patients is recommended, in order to estimate the role of small size of CGG repeat alleles in the aetiology of autism.
\end{abstract}

Keywords: Autistic Disorder, Fragile X Syndrome, Gene, Intermediate Alleles, Premutation Alleles

\section{Background}

Mutations in the fragile $\mathrm{X}$ mental retardation 1 gene are the most common single genetic cause of autismspectrum disorders. A number of individuals with Fragile X syndrome (FXS) have been shown to have some symptoms of autism such as hand flapping, poor eye contact, hand biting, perseveration in speech, and tactile defensiveness (1).The alleles are categorized according to the CGG repeat numbers as normal, intermediate (IM), premutation (PM), and full mutation. The normal or common size allele consists of 5 - 39 CGG repeats, intermediate alleles have approximately 40 - 54 CGG repeats, premutation alleles range from $55-200$ repeats, and the size range of full mutation alleles is $>200$ up to several thousand CGG repeats (2).

There is no linear correlation between the number of CGG repeats and clinical manifestations (3). In males with the full mutation, transcription is blocked due to methylation resulting gene silencing and usually affected. Approximately half of females with the full mutation have borderline IQs or are mentally retarded. Those with $\mathrm{m}$ typical IQ may have learning deficit or emotional symptoms (4). Formerly PM carriers, supposed to be clini- cally unaffected, are now known to be at increased risk of premature ovarian failure (POF) (OMIM \#311360), Fragile X-associated tremor/ataxia syndrome (FXTAS) (OMIM \#300623), autism (OMIM \#209850), emotional problems, late-onset neurodegenerative disorder, and neurocognitive deficits (3). The basis for the variable clinical presentation among individuals with IM and PM alleles is not exactly known. FMRP levels have commonly been thought to be normal for small alleles ( $<100$ repeats) and moderately decreased for larger PM alleles (5). Therefore, at the level of FMRP production, the model and clinical presentation are qualitatively consistent. While FMRP levels appear to be low in the upper PM range, due to a defect in the translation efficiency of the gene, the mRNA levels are actually high (6).

It is hypothesized that the presence of elevated levels of mRNA has a toxic "gain-of-function" effect as it has been proposed for the etiology of myotonic dystrophy (7). The presence of a pathology involving the PM allele would be of great importance given the high prevalence of these alleles in the general population. The lower limit of the premutation range remains imprecise. 
The clinical manifestations of PM alleles POF, autism, and FXTAS may result from this "mRNA poisoning" effect (3). It has been proposed that expansion in CGG repeat number results in elevated levels of transcripts, which interfere with the binding of several RNA-processing factors, generating novel forms of mRNA, and thus leading to functional changes in the corresponding proteins and progressive cell death (8) This mechanism has been supported by both and premutation mouse models $(9,10)$.

The impact of IM alleles (also known as 'grey zone' alleles) of CGG number is much less clinically understood. There are various definitions of intermediate alleles. Alleles in this range can be considered normal in the sense that such alleles have not been observed to expand to a full mutation in one generation although initially minor increases in repeat number can be observed in these alleles. A number of recent studies have demonstrated the elevation of mRNA levels in IM and PM CGG allele carriers with a lower threshold at 40 repeats (11). On this base, IM alleles have been categorized as 40 - 54 repeats throughout this paper. The frequency of IM alleles in various population samples is nearly $2 \%-3 \%(2,12)$. Furthermore, intermediate alleles have recently been considered to be associated with specific clinical phenotypes.

The first report of a clinical phenotype associated with intermediate alleles was "learning difficulties" in special educational needs children $(2,12-14)$. Two studies reported a significant increase of intermediate alleles in POF populations $(15,16)$. Previously, we showed that intermediate alleles are associated with parkinsonism (11), and also reported that epigenetic components might be involved in the toxicity of excessive mRNA in small size alleles (17). Our preliminary results showed that PM and IM alleles may be attributed to neurodevelopmental conditions (17). Therefore, current literature suggests autism and small size alleles might overlap. In this study, we screened DNA samples for the presence of IM or PM alleles in 96 autism patients and found significant excess of both alleles in comparison with control subjects.

\section{Methods}

This study was approved by the Tabriz University of Medical Sciences ethics committee. All patients and normal controls were of the same ethnicity, white Caucasians of Asian origin.

\subsection{Patient Subjects}

This study was designed to establish the frequencies of intermediate and premutation alleles among 96 males with Autistic disorder who were diagnosed by pediatric neurologists or psychiatrists and 132 male control subjects. Patients were employed based on clinical phenotype of DSM-IV criteria. The age of the patients was ranging from 2 years to 20 years, and that of the control subjects from $6-18$ years. There were no significant differences in age and ethnicity of the groups. All subjects participated in the study with informed consent, which has been approved by the ethical committee.

\subsection{Molecular Analysis}

Genomic DNA was extracted from whole blood based on salting out method (17). Pureness and amount of the isolated DNA samples were measured by spectrophotometry. Polymerase chain reaction (PCR) was performed using previously published protocol (18). The PCR amplification was carried out in a final reaction volume of $25 \mu \mathrm{L}$ containing $\sim 100 \mathrm{ng}$ of genomic DNA, $4 \mathrm{pmol} / \mathrm{l}$ of each primer, $2.5 \mu \mathrm{L}$ 10x PCR buffer, $0.25 \mathrm{mM}$ of each dNTP, $1.5 \mathrm{mM} \mathrm{MgCl}_{2}, 2$ units SmarTaq DNA polymerase (Cinnagen, Iran), and $2.5 \mu \mathrm{L}$ of Q solution.

The PCR cycling profile was as follows: initial denaturation at $98^{\circ} \mathrm{C}$ for 5 minutes; 35 cycles at $98^{\circ} \mathrm{C}$ for $45 \mathrm{sec}$ onds, $68^{\circ} \mathrm{C}$ for 30 seconds, $72^{\circ} \mathrm{C}$ for 1 minutes, and a final extension at $72^{\circ} \mathrm{C}$ for 10 minutes using the Gene Amp@ PCR System 9700 (Applied Biosystem). PCR products were visualized by $3 \%$ agarose gel electrophoresis and measured using standards and controls of 30- and 75-repeat lengths beforehand defined by sequencing method. In order to more accurately determine the CGG repeat size of samples were determined as IM or PM alleles in agarose electrophoresis were sequenced for CGG repeat tracts (Macro gene company, Seoul, South Korea). PCR products were purified and sequenced using the BigDye ve3.1 Terminator Cycle Sequencing kit (Applied Biosystems). Samples with no band in PCR were assumed as full mutation alleles and excluded from our study to be examined using Southern blot.

\section{Results}

All statistical analyses were carried out using the STATA statistical package and -value of 0.05 or below has been taken to be statistically significant. In this study, IM and PM alleles have been classified as 40 - 54 and 55 - 200 repeats, respectively. Three mutated, five intermediate, and four premutation carriers were identified among Autistic patients. In normal controls no intermediate, no full mutation alleles, and one premutation carrier were observed, representing a noteworthy excess in small size FMR1 allele carriers.

First, we compared the distribution of alleles using Fisher's exact and chi-squared tests and demonstrated a 
highly significant increase in the proportions of small CGG FMR1 alleles (IM and PM alleles) in Autism subjects compared with male control. Ten intermediate and premutation carriers (CGG repeat numbers equal 44, 48, 51, 51, 58, 75, 90, 95 and103) were found among 96 Autism patients, compared with one in 168 normal controls, representing a significant excess (two-sided Fisher's exact test, -value = 0.0006 and two-side chi-squared P value $<0.0003$ ) ( Table 1).

Table 1. Comparison of Frequencies of CGG Allele Categories Between Autism Patients and Control Group (Normal: 0 - 40 Repeats; Intermediate: 40 - 60 Repeats; Premutation 61-200 Repeats) ${ }^{\mathrm{a}}$

\begin{tabular}{lccc}
\hline \multirow{2}{*}{ Sample } & \multicolumn{2}{c}{ CGG Categories } & \multirow{2}{*}{ Total } \\
\cline { 2 - 3 } & $\mathbf{0 - 3 9}$ & $\mathbf{4 0 - 5 4}$ and $\mathbf{5 4 - 2 0 0}$ & \\
\hline Control & 167 & 1 & 168 \\
Autism & 87 & 9 & 96 \\
Total & 254 & 10 & 264 \\
\hline
\end{tabular}

${ }^{\mathrm{a}}$ Fisher's two-sided -value $=0.0006$, Chi-square two-sided -value $=0.0003$.

Using the same method, we also demonstrated a significant increase in the proportion of intermediate alleles in Autism subjects compared with male controls (two-sided Fisher's exact test, -value $=0.006$ and two-side chi-squared -value $=0.002)($ Table 2$)$.

Table 2. Comparison of Frequencies of CGG Allele Categories Between AD and Control Group (Normal: 0 - 40 Repeats; Intermediate: 40 - 60 Repeats) ${ }^{\mathrm{a}}$

\begin{tabular}{lccc}
\hline \multirow{2}{*}{ Sample } & \multicolumn{2}{c}{ CGG Categories } & \multirow{2}{*}{ Total } \\
\cline { 2 - 3 } & $\mathbf{0 - 3 9}$ & $\mathbf{4 0 - 5 4}$ & \\
\hline Control & 168 & 0 & 168 \\
Autism & 91 & 5 & 96 \\
Total & 259 & 5 & 264 \\
\hline
\end{tabular}

${ }^{\mathrm{a}}$ Fisher's two-sided P value $=0.006$, Chi-square two-sided -value $=0.002$

Three patients, in whom DNA was not amplified, were assumed to be fully mutated. Their agarose gel electrophoresis results displayed full mutation by lack of amplification, because of large expansions. No full mutation was found in the control population.

\section{Discussion}

During last decades, the established molecular model offering that neuropsychological abnormalities in Fragile $\mathrm{X}$ result from significant loss of FMRP production has been revised. There are many reports that PM CGG alleles have clinically effects, despite normal FMRP protein. In this study, it was hypothesized that IM-size alleles may play some role in the cause of autism disorders. This was based on the earlier finding (11) that the level of mRNA in individuals with intermediate CGG repeat size alleles is similar to that associated with PM alleles which are known to be associated with some neurodevelopmental conditions and late onset tremor ataxia (FXTAS) (19). Autism is currently considered to be a multifactorial disorder that involves a strong genetic influence (20). Identification of molecular factors that account for the development of autism is currently an area of extensive research. It has been shown as a part of the behavioral phenotype in several genetic disorders, including FXS, phenylketonuria (PKU), tuberous sclerosis, Rett syndrome, and duplications in chromosome $15 \mathrm{q}$ (21-23).

There is a clear correlation between FMRP concentration and mean scores of childhood autism rating scale (CARS); the lower FMRP concentration, the lower CARS in autistic child. It has been reported that individuals with FXS autism had a lower IQ than non-autistic individuals with FXS alone (24). So far, clinical involvement of intermediate size alleles has been proved in POF, but not much evidence has been presented for neurodegenerative and neurodevelopmental disorders. The association of small CGG repeat expansion FMR1 alleles with parkinsonism and autistic phenotype in Australian population has been presented $(17,25,26)$. We continued our research in other ethnic groups in order to confirm pervious findings. Therefore, FMR1 intermediate alleles among 96 autistic males were screened and IM-size alleles in five autistic males were found, with prevalence close to $5 \%$. The role of IM alleles in autistic disorder and any behavioral and/or cognitive phenotypes is controversial. Several studies report an association of IM alleles with an increased risk of autismspectrum disorders $(5,17)$. Their findings revealed a high occurrence of IM alleles that has also been related to an increased risk of behavioral phenotypes (1). Other studies failed to replicate these findings. In Spain and Japan, the frequency of IM alleles were screened among autistic patients and showed no association between IM alleles and increased risk of Autistic disorder $(27,28)$. This study was planned to obtain additional data and may help to resolve this controversy. Our data from the samples of males with autism suggest that intermediate alleles may play a part in the etiology of some forms of idiopathic autism and recommended our pervious published results (25). Considering that one in 30 - 40 individuals in the general population is a carrier of an intermediate size allele, the potential significance of these findings is obvious, and further screening of well-powered cohorts of patients with autism, as well as detailed neurological examinations is warranted (17). 
Despite the small sample size in this study, our findings add weight to the suggestion that IM alleles of CGG repeats have specific clinical manifestations and should be considered as a risk factor for Autistic disorder. However, these results need to be duplicated in other independent samples and larger populations. More studies are required with large number of case and control populations from different ethnic groups to prove that intermediate alleles can contribute to the etiology of neurodevelopmental and neurodegenerative disorders. If these recent results can be replicated in other independent samples using a larger population-based control sample, it will open a new area of examination into molecular patho-mechanisms of the smallest CGG expansions and their impact on clinical phenotype.

\section{Acknowledgments}

This study was funded by Tabriz University of Medical Sciences. We would like to thank autistic patients and their families for their involvement in our study. We also thank Tabriz Autism society that helped with samplings. Finally, we need to thank Tabriz Ebne Sina Medical Genetic Center for performing molecular analyses.

\section{References}

1. Loesch DZ, Bui QM, Dissanayake C, Clifford S, Gould E, Bulhak-Paterson $D$, et al. Molecular and cognitive predictors of the continuum of autistic behaviours in fragile X. Neurosci Biobehav Rev. 2007;31(3):315-26. doi: 10.1016/j.neubiorev.2006.09.007. [PubMed:17097142].

2. Mitchell RJ, Holden JJ, Zhang C, Curlis Y, Slater HR, Burgess T, et al. FMR1 alleles in Tasmania: a screening study of the special educational needs population. Clin Genet. 2005;67(1):38-46. doi: 10.1111/j.13990004.2004.00344.x. [PubMed: 15617547].

3. Jacquemont S, Hagerman RJ, Hagerman PJ, Leehey MA. Fragile-X syndrome and fragile $\mathrm{X}$-associated tremor/ataxia syndrome: two faces of FMR1. Lancet Neurol. 2007;6(1):45-55. doi: 10.1016/S14744422(06)70676-7. [PubMed: 17166801].

4. Loesch DZ, Huggins RM, Hagerman RJ. Phenotypic variation and FMRP levels in fragile X. Ment Retard Dev Disabil Res Rev. 2004;10(1):3141. doi: 10.1002/mrdd.20006. [PubMed: 14994286].

5. Tassone F, Beilina A, Carosi C, Albertosi S, Bagni C, Li L, et al. Elevated FMR1 mRNA in premutation carriers is due to increased transcription. RNA. 2007;13(4):555-62. doi: 10.1261/rna.280807. [PubMed: 17283214].

6. Leehey MA, Berry-Kravis E, Min SJ, Hall DA, Rice CD, Zhang L, et al. Progression of tremor and ataxia in male carriers of the FMR1 premutation. Mov Disord. 2007;22(2):203-6. doi: 10.1002/mds.21252. [PubMed: 17133502]

7. Ranum LP, Day JW. Myotonic dystrophy: clinical and molecular parallels between myotonic dystrophy type 1 and type 2. Curr Neurol Neurosci Rep. 2002;2(5):465-70. [PubMed: 12169228].

8. Galvao R, Mendes-Soares L, Camara J, Jaco I, Carmo-Fonseca M. Triplet repeats, RNA secondary structure and toxic gain-of-function models for pathogenesis. Brain Res Bull. 2001;56(3-4):191-201. [PubMed: 11719250].

9. Jin P, Zarnescu DC, Zhang F, Pearson CE, Lucchesi JC, Moses K, et al. RNA-mediated neurodegeneration caused by the fragile $\mathrm{X}$ premutation rCGG repeats in Drosophila. Neuron. 2003;39(5):739-47. [PubMed: 12948442].
10. Willemsen R, Hoogeveen-Westerveld M, Reis S, Holstege J, Severijnen LA, Nieuwenhuizen IM, et al. The FMR1 CGG repeat mouse displays ubiquitin-positive intranuclear neuronal inclusions; implications for the cerebellar tremor/ataxia syndrome. Hum Mol Genet. 2003;12(9):949-59. [PubMed: 12700164].

11. Loesch DZ, Bui QM, Huggins RM, Mitchell RJ, Hagerman RJ, Tassone F. Transcript levels of the intermediate size or grey zone fragile X mental retardation 1 alleles are raised, and correlate with the number of CGG repeats.J Med Genet. 2007;44(3):200-4. doi:10.1136/jmg.2006.043950. [PubMed: 16905681]

12. Youings SA, Murray A, Dennis N, Ennis S, Lewis C, McKechnie N, et al. FRAXA and FRAXE: the results of a five year survey. J Med Genet 2000;37(6):415-21. [PubMed: 10851251].

13. Castellvi-Bel S, Fernandez-Burriel M, Rife M, Jimenez D, Mallolas J, Sanchez A, et al. Detection of the fragile X syndrome protein for the evaluation of FMR1 intermediate alleles. Hum Genet. 2000;107(2):1956. [PubMed: 11030419].

14. Mazzocco MM, Sonna NL, Teisl JT, Pinit A, Shapiro BK, Shah N, et al. The FMR1 and FMR2 mutations are not common etiologies of academic difficulty among school-age children. J Dev Behav Pediatr 1997;18(6):392-8. [PubMed: 9431501].

15. Bretherick KL, Fluker MR, Robinson WP. FMR1 repeat sizes in the gray zone and high end of the normal range are associated with premature ovarian failure. Hum Genet. 2005;117(4):376-82. doi: 10.1007/s00439-005-1326-8. [PubMed: 16078053].

16. Bodega B, Bione S, Dalpra L, Toniolo D, Ornaghi F, Vegetti W, et al. Influence of intermediate and uninterrupted FMR1 CGG expansions in premature ovarian failure manifestation. Hum Reprod. 2006;21(4):952-7. doi: 10.1093/humrep/dei432. [PubMed:16361284].

17. Loesch DZ, Godler DE, Khaniani M, Gould E, Gehling F, Dissanayake C, et al. Linking the FMR1 alleles with small CGG expansions with neurodevelopmental disorders: preliminary data suggest an involvement of epigenetic mechanisms. Am J Med Genet A. 2009;149A(10):2306-10. doi: 10.1002/ajmg.a.32990. [PubMed: 19760650].

18. Khaniani MS, Kalitsis P, Burgess T, Slater HR. An improved Diagnostic PCR Assay for identification of Cryptic Heterozygosity for CGG Triplet Repeat Alleles in the Fragile X Gene (FMR1). Mol Cytogenet. 2008;1:5. doi: 10.1186/1755-8166-1-5. [PubMed: 18471319].

19. Hagerman RJ, Leehey M, Heinrichs W, Tassone F, Wilson R, Hills J, et al. Intention tremor, parkinsonism, and generalized brain atrophy in male carriers of fragile X. Neurology. 2001;57(1):127-30. [PubMed: 11445641].

20. Scambler DJ, Hepburn SL, Hagerman RJ, Rogers SJ. A preliminary study of screening for risk of autism in children with fragile X syndrome: testing two risk cut-offs for the Checklist for Autism in Toddlers. J Intellect Disabil Res. 2007;51(Pt 4):269-76. doi: 10.1111/j.13652788.2006.00874.x. [PubMed: 17326808].

21. Autism Genome Project C, Szatmari P, Paterson AD, Zwaigenbaum L, Roberts W, Brian J, et al. Mapping autism risk loci using genetic linkage and chromosomal rearrangements. Nat Genet. 2007;39(3):319-28. doi: $10.1038 /$ ng1985. [PubMed: 17322880].

22. Gillberg C. Chromosomal disorders and autism. J Autism Dev Disord. 1998;28(5):415-25. [PubMed: 9813777]

23. Hou M, Wang MJ, Zhong N. Principal genetic syndromes and autism: from phenotypes, proteins to genes. Beijing Da Xue Xue Bao. 2006;38(1):110-5. [PubMed: 16415981].

24. Farzin F, Perry H, Hessl D, Loesch D, Cohen J, Bacalman S, et al. Autism spectrum disorders and attention-deficit/hyperactivity disorder in boys with the fragile X premutation. J Dev Behav Pediatr. 2006;27(2 Suppl):S137-44. [PubMed: 16685180].

25. Loesch DZ, Khaniani MS, Slater HR, Rubio JP, Bui QM, Kotschet K, et al. Small CGG repeat expansion alleles of FMR1 gene are associated 
with parkinsonism. Clin Genet. 2009;76(5):471-6. doi: 10.1111/j.13990004.2009.01275.x. [PubMed: 19796183].

26. Liu Y, Winarni TI, Zhang L, Tassone F, Hagerman RJ. Fragile Xassociated tremor/ataxia syndrome (FXTAS) in grey zone carriers. Clin Genet. 2013;84(1):74-7. doi: 10.111//cge.12026. [PubMed: 23009394].

27. Otsuka S, Sakamoto Y, Siomi H, Itakura M, Yamamoto K, Matumoto H, et al. Fragile X carrier screening and FMR1 allele distribu- tion in the Japanese population. Brain Dev. 2010;32(2):110-4. doi: 10.1016/j.braindev.2008.12.015. [PubMed: 19211207].

28. Madrigal I, Xuncla M, Tejada MI, Martinez F, Fernandez-Carvajal I, Perez-Jurado LA, et al. Intermediate FMR1 alleles and cognitive and/or behavioural phenotypes. EurJHum Genet. 2011;19(8):921-3. doi: 10.1038/ejhg.2011.41. [PubMed: 21427756]. 